\title{
THE SCHIZOPHRENIG MALADJUSTMENT.*
}

\author{
$\mathrm{BY}$
}

\section{MACFIE CAMPBELL, Boston, Mass.}

AmoNG the maladjustments of man to his environment there are none more dramatic than those found in the field of mental disorders. In this field one meets disorders of human adaptation of the greatest variety. It includes cases where adaptation has been seriously hampered by gross structural brain disease ; at the other extreme it includes hysterical cases where, for instance, a paralysis is found with no evidence of any structural damage. Viewed from the standpoint of the adjustment of the individual to the environment, these two extreme types of disorders represent very different problems. In the organic psychoses with gross brain disease, where there may be definite motor defects, loss of memory, inability to deal with situations with good practical judgment, the picture is one of an actual defect, of loss or reduction of function - the loss being intelligible in the light of structural damage, but not having any particular significance or playing any active rôle in the adjustment of the individual to the life situation. It is somewhat different in cases of hysteria where one meets symptoms superficially somewhat similar, such as paralysis, blindness, memory defect, but where the symptoms are not to be looked upon in a negative way as a defect, which impairs the working of the machine, but where they are to be considered in a positive way, as having meaning, or significance, and playing a definite rôle in the adjustment of the individual to the life situation. This hysterical adjustment may receive a judgment of value from others who condemn it as one of inferior quality; at any rate adjustment has been made, which, while socially inferior, may have its own value for the individual. In the organic psychoses the defect has no value for the individual, or if it does have a certain value as in relation to pensions and compensations, that value is a secondary matter and is absolutely irrelevant to the development of the defect. The paraplegia which enables the hysteric to avoid the danger of battle or the effort of industry by means of his apparent invalidism, is part of an adjustment, while the paraplegia of a cord tumour is a mere defect without meaning.

In our study of mental disorders in general it makes a very great deal of difference whether we consider exclusively the principles which dominate the study of the organic psychoses, or whether we utilize the point of view which has thrown so much light on hysteria and the other psychoneuroses. It makes a great difference whether we consider symptoms as defects or anomalies

* Read at a symposium on Maladjustments at the Ninth International Congress of Psychology, Yale University, New Haven, Septemher 1929. 
dependent on some structural or toxic damage to the nervous system, or whether we scrutinize each symptom and syndrome as possibly having significance, and as being part of an attempted adjustment to a life situation. The one attitude does not exclude but should supplement the other. A symptom may have its origin in certain structural or toxic factors, while at the same time it may be utilized for adaptive purposes ; the severity and duration of the symptom may only be intelligible in the light of the actual situation and of the strivings of the individual.

When the study of mental disorders became possible through emancipation from mediæval ideas of possession the first tendency was to assimilate the study of the symptoms of mental disorders to the study of physical diseases, and to look for their explanation in terms of structural and clinical pathology. Histopathological and biochemical studies have been very illuminating; the symptoms in the organic and toxic psychoses become more intelligible in the light of definite cortical and subcortical lesions, of inflammatory processes and metabolic disorders. Notwithstanding the prestige due to these discoveries and the desire of some workers in these fields to extend their formulations over the general field of mental disorders, it became evident that investigation along these lines had thrown little light on the so-called functional psychoses. Hysteria and the other psychoneuroses had been illuminated when the symptoms were studied in the setting of the adjustment of the individual to the environment, when adequate recognition was given to the complexity of human nature and to the actual significance of the life situation to which the patient had to adjust. The progress made in the study of the psychoneuroses stimulated a reorientation in the study of the functional psychoses, and the stimulus given to this new orientation by the formulations of Adolf Meyer and of Jung on the schizophrenic group has done much to direct the work of the last two decades. While the main principles were thus clearly outlined twenty years ago, the necessity for the painstaking accumulation of well-analysed material still exists. In the field of psychiatry the experimental method has strict limits, and in view of our inability to experiment with the main issues of life it behoves us to gather carefully all we can from the ruthless experiments of nature.

The technical difficulties in the accurate analysis of this material are considerable. The schizophrenic group of psychoses is by no means easy to delimit, and there is no general consensus of opinion as to the exact criteria which entitle a case to be included in this group. In this communication the term schizophrenia is provisionally used in a rather broad way to indicate a group of cases of the greatest diversity as to both symptomatology and course ; in general the patient in this group has a formulation of experience, which contains elements so odd and unusual, that they seem completely alien to the structure of the normal mind. This alien appearance may, however, be due not so much to a real lack of kinship with the normal mind, as to the fact that 
we are much less familiar with the organization of the latter than we have been wont to assume. The study of problems of the normal adult mind in laboratories of experimental psychology had not revealed the persistence of childhood and primitive modes of experience beneath the conscious processes of the modern adult, nor the full importance of the sex factor with its tributaries from infantile and juvenile sources.

With a fuller appreciation of these latter factors the behaviour and utterances of the schizophrenic seem less meaningless; we realize, however, that in studying the latter we have to understand a new idiom. The idiom is much simpler in some cases than in others; the degree to which it renders intelligible the schizophrenic experience is variable. Even with some knowledge of the schizophrenic idiom the total manifestations may appear to be only in part adaptive and with meaning, and some symptoms seem to have no more significance than defect or irritative symptoms of organic or toxic origin.

A young woman claims that she has two selves, the new self on the left, the old self on the right of her body; she is to be the mother of God; she became pregnant (there was no pregnancy) without coitus, she has had sex relations with God; she has seen and spoken with God.

These beliefs are quite alien to her organized body of knowledge, but represent obviously not merely a defective mode of thought of no adaptive significance or value ; the girl has been brought up in a strictly religious family, her acquaintanceship with boys was severely restricted, she has been found unsuited for the religious life. She develops an experience which satisfies her sexual and religious cravings, while she recognizes the conflict between the different forces in her nature.

Is such a surrender to the imaginative satisfaction of cravings and such acceptance of the naive formulation of the two selves possible without a defect of organic or toxic origin? In answering the question one must consider not only the data of the various laboratories but also the facts of the religious life in general. The latter may require critical scrutiny, but they too represent valuable experiments of nature in which personalities of various types have been faced with a great variety of situations.

In the present case the girl, of imaginative nature, steeped in a religious atmosphere, had reacted to the restrictions and values of the social environment with a passive acceptance of real deprivation but with intense absorption in imaginative realization of her cravings.

In other cases the reaction of the patient is not so simple as in this example of indulgence in undisguised imaginative satisfaction.

Thus a woman in the forties, married to an impotent husband, begins to complain that the house is wired with electricity by her husband to annoy her, that the 'movies' demonstrate her life and at the same time use plots plagiarized from her, that spirits of dead artists commune with her. She berates a woman because the latter makes a gesture signifying "you take her, she's yours!" 
In this case the experience seems more remote from the structure of our everyday experience than that of the religious girl referred to. It is true that the feeling of the presence of the spirits of the great artists of the past is sufficiently close to the religious experience; but the distorted view of the environment ("wired with electricity"), the complicated interpretation of the 'movies,' and of the trivial gestures of strangers, are not simply related to any familiar emotional craving. One might be inclined, therefore, to say that the distorted structure of this patient's experience was only to a slight degree intelligible as an adjustment to the actual life situation, and on the whole was a meaningless disturbance of the thought functions.

While the latter is possible, it is well to do justice to the actual nature of the symptoms. The patient's reference to the house being all maliciously " wired with electricity" by her husband, may be her way of meeting the actual feelings due to the unsatisfactory marital relations ; instead of thinking clearly and realistically about the disturbing sexual factor, she finds it more tolerable to think of it in less direct and less adequate terms, in terms of electricity, for which she has no personal responsibility. Such a solution of a problem in sexual adjustment is sufficiently familiar. Such an interpretation can be sufficiently documented from a wide clinical material so that in the individual case it loses its arbitrary and a priori appearance.

The interpretation of the 'movies' and of the gestures of casual strangers dəmands a detailed analysis of the structure of experience and the recognition not only of repressed factors of emotional importance, dissociated from the rest of the conscious life, but also of the persistence in the adult of primitive and childlike modes of thought (Jung, Storch). It is one of the present tasks of psychiatry to collect material which will show to what extent these primitive and childlike modes of thought lie dormant beneath the surface of ordinary adult thought, as the primitive mass-reflex lies unnoticed in the highly integrated activities of the intact spinal cord.

The two cases cited above present a comparatively simple clinical picture ; in other cases one finds a much deeper disturbance of the organization of thought and behaviour with complete neglect of logical canons, great fluidity of concepts, parplexing statements without propositional form, neologisms, with equally marked disorders of behaviour. Under stress and strain human nature can go very far in the way of deviation from rational thought and action in an evasive, imaginative and regressive direction, with the reactivation of discarded modes of experience and with the disguised manifestations of crude and repressed instinctive tendencies, where there is no unequivocal evidence of any primary structural damage or intoxication. In many cases the disturbance of conduct and utterances is so profound that some take for granted that there must be some definite break and some irreparable damage to allow of such a degradation of human behaviour, and yet one may see the return from such a condition to complete previous normality with no indication of anything having been permanently lost. 
While the schizophrenic disorder is to a large extent intelligible as the reaction to the life-situation, the latter need not be of any dramatic quality. In the history of the patient as recorded one may note no outstanding event or situation which seems to involve undue strain, and conditioning factors of importance in early life may have escaped the notice of those near to the patient.

When one scrutinizes the symptoms of the psychosis and when one reviews with the patient the various steps in his experience one appreciates better the rôle which the actual life situation has played in the whole development. While banal as seen from the outside it may have been the very stuff out of which the special personality of the patient was likely to weave the abnormal fabric of its experience.

The adult environment may be of very normal appearance and the early moulding forces of the patient's life may seem to have been little different from those of his fellows, but the unobtrusive forces of the environment may have subtly and profoundly influenced his adjustment to the insistent demands of sex, to the bond between parent and child, to the opinion of his fellows, to the spiritual versus the material values of experience, and may have modified the vulnerability of the personality in relation to the tests of the adult life. This vulnerability, partly determined by congenital endowment, is also influenced by a long series of situations and experiences, the significance of which is apt to be overlooked.

The overt səries of reactions, which constitute the psychosis, is often but the later stage of a maladjustment which stretches far back to the childhood of the patient. The study of the etiology of a schizophrenic psychosis is the study of the action and interaction of an individual and his environment over a long period, and throws light on many phases and varieties of human maladjustment. 